\title{
From Waste to Resource: Can Selective Collection Really Help?
}

\author{
Elena Cristina Rada* \\ Department of Civil Environmental and Mechanical Engineering, University of Trento, I-38050 Trento, Italy
}

The municipal solid waste (MSW) generation depends on the industrialisation and the sustained growth population in the world. The first data regarding the people waste production referred to the Paleolithic era, thanks to the Absolon discovery in 1945 [1]. During the years the composition of MSW was on continuous changes. For example a century ago the MSW contained mainly coal ash and food scraps, with a small proportion of paper and glass [2]. Instead today after the economic-industrial development in the MSW it can be found a high quantity of organic and packaging materials and only a very low quantity of inorganic ones.

The first concept of waste selective collection (kerbside) and open dumps constructed at about $2 \mathrm{~km}$ away from the cities, date back to the birth of the first civilization in 2000 B.C. [3]. However in the 1960s, 1970s, and 1980s, the waste Selective Collection (SC) was implemented more and more in order to reduce the waste flow sent to landfills [4] and incinerators whilst municipalities were considered responsible for recycling collection [5].

The waste SC during the years has been one of the most discussed topics in the scientific sector [6]. The first proposed treatment for the selected organic waste was the composting one [7], followed by anaerobic digestion [8], whilst biostabilization [9] and biodrying [10] are involved if food waste SC shows a low quality.

In the last years, in European Union, with the introduction of the Waste Framework Directive (2008/98/EC) that established a target of re-use/recycling/valorization of at least $50 \%$ of household waste by 2020 this situation is changing putting the attention on MSW as "future resource".

The question raised in the latest years, regards the efficient use of SC in order to transform the MSW in materials that can be re-used by recycling as glass, PET, paper and cardboard, organic fraction and the remaining ones, the "residual MSW" that can be reused as a solid recovered fuel (SRF) in order to substitute fossil combustible [11].

In the MSW sector the following questions, often related with the SRF that will be produced after an extreme SC, represent the main topics on the carpet and the priorities of the international research:

- Does the residual MSW will be directly suitable as SRF? This opportunity could decrease the costs for waste management as a complex mechanical-biological treatment could be avoided.

- Does extreme SC efficiencies could decrease the amount of residual MSW to levels often not compatible with the construction of an incinerator? In the sector it is clear that the scale effect plays and important role in the feasibility of an incinerator, thus in the future some regions could renounce to the construction of such a plant as a consequence of the evolution of SC; the option of SRF generation could become more and more attractive.

- Does SC and streams valorisation give to residual MSW a secondary role? Where selective collection has got the best results in harmony with valorisation strategies, residual MSW can be reduced to about $20 \%$ of the generated MSW.

- Does SC open to unconventional strategies of material valorisation? Top results in SC generate source-separated streams that never in the past were taken into account; an example is the diapers SC that requires, for a correct valorisation, the construction of a treatment plant suitable for separating the cellulosic and plastic materials used for this product.

In this frame it is clear that only a high quality SC can help in changing the role of MSW: from waste to resource.

Finally, as an opportunity to increase the know-how of the sector, the open access journals and specifically the OMICS Group activities are contributing to have a complete scientific answer to the above questions.

\section{References}

1. CAC (1998) Cooperative Atlantis of Cervia the city school project Waste: Energy of the future.

2. Morse WF (1908) The Collection and Disposal of Municipal Waste. The Municipal Journal and Engineer. New York USA.

3. Santoloci M, Vattani $V$ (2009) Solid and liquid waste: management, transportation, storage, depots and surroundings. Right environment editions, Terni.

4. Rada EC (2012) Biodegradability of Landfilled MSW in EU: Past, Present and Future. Journal of Bioremediation and Biodegradation 3:1-2.

5. Spiegelman H, Sheehan B (2005) Unintended consequences: Municipal Solid Waste management and the throwaway society Product Policy Institute.

6. Rada EC (2013) Effects of MSW selective collection on waste-to-energy strategies. Energy and Sustainability 4: 215-223.

7. Gotaas HB (1956) Composting sanitary disposal and reclamation of organic wastes. Monograph series WHO 31: 1-205.

8. Johnson GE, Kunka LM, Decker WA, Forney AJ (1972) Production of methane by the anerobic decomposition of garbage and waste materials. American Chemical Society Division Fuel Chemistry 16: 70-78.

9. Adani F, Scatigna L, Genevini P (2000) Biostabilization of mechanically separated municipal solid waste fraction. Waste Management and Research 18: $471-477$.

10. Rada EC, Ragazzi M, Badea A (2012) MSW Bio drying: Design criteria from A 10 years research UPB Scientific Bulletin 74: 209-216.

11. Ionescu G, Rada EC, Ragazzi M, Marculescu C, Badea A, et al. (2013) Integrated municipal solid waste scenario model using advanced pretreatment and waste to energy processes, Energy Conversion and Management 76: 1083-1092.

*Corresponding author: Elena Cristina Rada, Department of Civil Environmental and Mechanical Engineering, University of Trento, Italy; Fax: +39 0461282672; Tel: +39 0461282605; E-mail: Elena.Rada@unitn.it

Received November 16, 2013; Accepted November 17, 2013; Published November 22, 2013

Citation: Rada EC (2013) From Waste to Resource: Can Selective Collection Really Help? Int J Waste Resources 3: e103. doi: 10.4172/2252-5211.1000e103

Copyright: (C) 2013 Rada EC. This is an open-access article distributed under the terms of the Creative Commons Attribution License, which permits unrestricted use, distribution, and reproduction in any medium, provided the original author and source are credited. 